\title{
Infrared Techniques for Practical Defect Identification in Bonded Joints in Liquefied Natural Gas Carriers
}

\author{
R.C. Tighe ${ }^{1}$ - J.M. Dulieu-Barton ${ }^{1} \cdot$ S. Quinn ${ }^{1}$
}

Received: 27 January 2017 / Accepted: 30 July 2017 / Published online: 28 August 2017

(C) The Author(s) 2017. This article is an open access publication

\begin{abstract}
A robust and reliable method for the identification of defects in adhesively bonded joints used in the membrane containment system used to store liquefied natural gas during transport on board ships is required. The adhesively bonded interface of the membrane system may contain low volume defects known as kissing defects, which are extremely difficult to detect using portable inspection techniques. A novel methodology for detecting such defects is described in the paper. To demonstrate the approach simulated kissing defects were produced in a controlled fashion in a representative secondary membrane bond using silicon grease contamination. The defects were detected using an active thermographic approach known as pulsed phase thermography (PPT) which detects subsurface defects by monitoring the effect they have on the propagation of heat through a component. Due to the low volume of kissing defects, they generally have minimal effect on the heat propagation, so the detection was made possible by application of a small load generated by application of a vacuum. The vacuum can be set-up using a reusable chamber and a standard vacuum pump and therefore is portable and can be applied on-site and in a shipyard during construction.
\end{abstract}

Keywords Pulse phase thermography · GTT Mk III · Vacuum loading $\cdot$ Liquefied natural gas carriers

R.C. Tighe

RCTighe36@gmail.com

1 Faculty of Engineering and the Environment, University of Southampton, Southampton SO17 1BJ, UK

\section{Introduction}

Natural gas provides $47 \%$ of electricity in the UK [1] and accounts for $25 \%$ of global energy. Of this global use $10 \%$ is supplied as liquefied natural gas (LNG) [2]. With the decrease of local sources and a need to diversify supply chains a larger percentage of this gas is set to come via the sea, aboard large carriers as liquefied natural gas (LNG). Of the 410 LNG carriers active in $2015,76 \%$ have membrane style containment systems [2]. The membrane containment system consists of a metallic primary membrane, responsible for containing the LNG and a secondary membrane. The GTT Mk III system is a membrane style LNG containment system where the secondary membrane is formed using Triplex ${ }^{\mathrm{TM}}$. An alternative secondary membrane material of Invar with welded joints is also used, however, due to the welded joints; this is not the subject of the present paper. Triplex is a composite material composed of a $0.6 \mathrm{~mm}$ layer of aluminium with a layer of glass fibre cloth on either side [3, 4]. There are two types of Triplex: rigid, which contains a resin with a high Young's modulus or, flexible, which incorporates a resin with a lower Young's modulus. The Mk III containment system is formed in prefabricated sections which are then installed in the carrier. The prefabricated sections include the rigid Triplex. The flexible Triplex is then used to bond two adjoining pieces of rigid Triplex together to form a continuous secondary containment system, as shown in Fig. 1(a) and (b). The purpose of the secondary membrane is to protect the ship's hull from exposure to LNG if the primary membrane were to fail. To ensure the integrity of the secondary membrane it is necessary to inspect the quality of the adhesive bond and detect any defects that may have been introduced during manufacture. The total length of adhesive bond found in current Mk III carriers is over $50 \mathrm{~km}$, and with an expected increase in carrier size this is set to more than double [3]. It is paramount that these bonds 


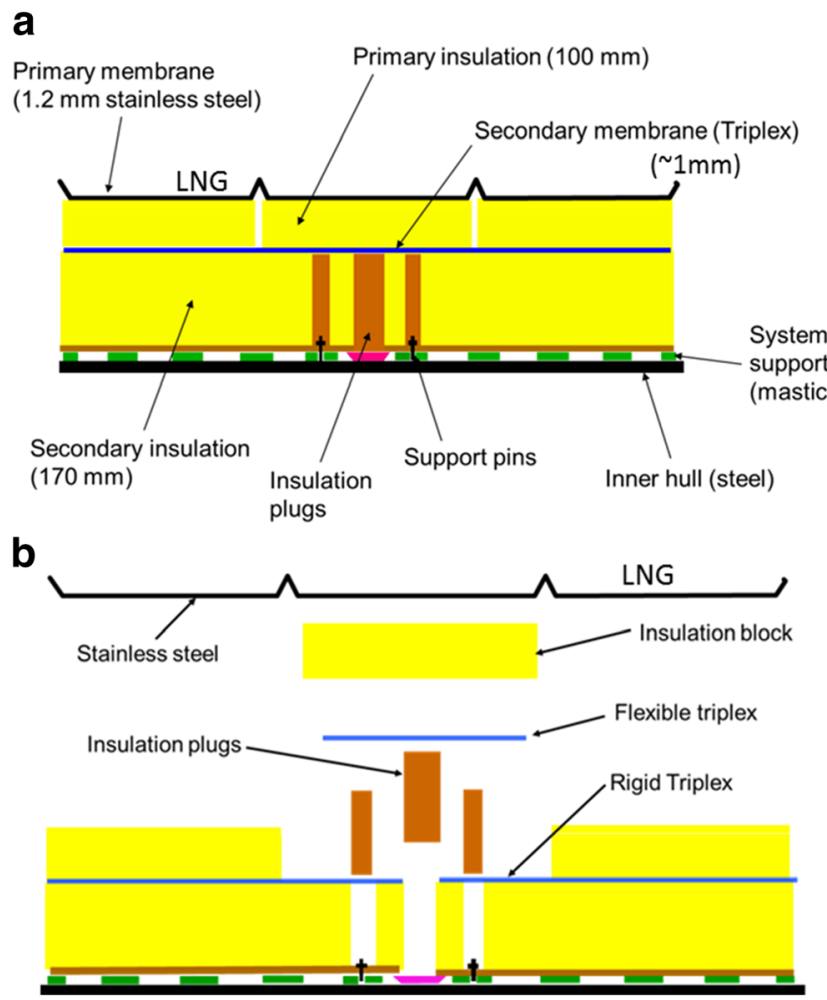

Fig. 1 (a) Schematic of GTT Mk III LNG carrier bonded joint and (b) in shipyard construction of the secondary membrane [3]

are thoroughly inspected during manufacture as, once approved, they are sealed below thermal insulation and the metallic primary membrane and so are no longer accessible for inspection. It is assumed by the manufacturers that once the bond is inspected during the construction stages and approved that it will remain approved through life. Should any subsequent inspections be required it would be necessary to dismanthe the primary membrane and insulation layers, hence it is of paramount importance that the bonds be suitably inspected to avoid costly remedial work.

Current non-destructive evaluation (NDE) techniques for the LNG containment systems are based upon traditional approaches, which are either global or local. The global approach is termed a total tightness test where the complete unit is inspected in its entirety by filling with air and monitoring for leaks using acoustic sensors [3]. While current global techniques may identify a leak these tests may only be carried out upon completion of the full membrane and are time consuming due to the requirement to pressurise the whole section of the containment system. If a defect is found costly rework is required and the test must be carried out again to check the repair. Local techniques are based on manual approaches such as visual inspections and tap tests that inspect a very small area at once [3]. This generally results in only selected areas of higher risk being inspected using such approaches. Visual inspection can be carried out using a light source to highlight bubbles in the bond or by inspecting the edges of the adhesive bond where the adhesive exceeds the bonded area. Should this visible adhesive contain bubbles the assumption is that the adhesive in the bond also contains air bubbles and hence fails the inspection. To inspect the full length of adhesive bonds using a local measurement such as a tap test would take a prohibitively long time.

As has been shown current inspection approaches are either extremely labour intensive or are carried out too late which leads to a costly repair. Therefore, a NDE technique is required that can fully inspect the Triplex adhesive bonds during manufacture, to enable defects to be identified during construction and enable timely remedial work and reduction of waste material.

To effectively inspect the Triplex bonds there are several requirements to be considered:

1) The bonds are only accessible from one side as the Triplex membrane is fixed to a layer of thermal insulation which is fixed to the inner hull of the carrier.

2) The technique must be efficient as there are over $50 \mathrm{~km}$ of bonds to inspect in a single carrier.

3) The technique must be portable and sufficiently robust to be used in a shipyard.

4) All types of defects likely to occur in the adhesive bonds must be detected, especially the elusive kissing defects.

5) The results of the technique must be easy to interpret by trained personnel.

\section{Adhesive Bonds}

Several types of defects occur in adhesive bonds $[5,6]$. These may be considered to fall into three main categories, see Fig. 2 . The first type are inclusions, which are the physical inclusion of a foreign material in the adhesive joint, as in Fig. 2(a). These could occur, for example, if positioning tape is left on the adherend (material being bonded) and has adhesive applied

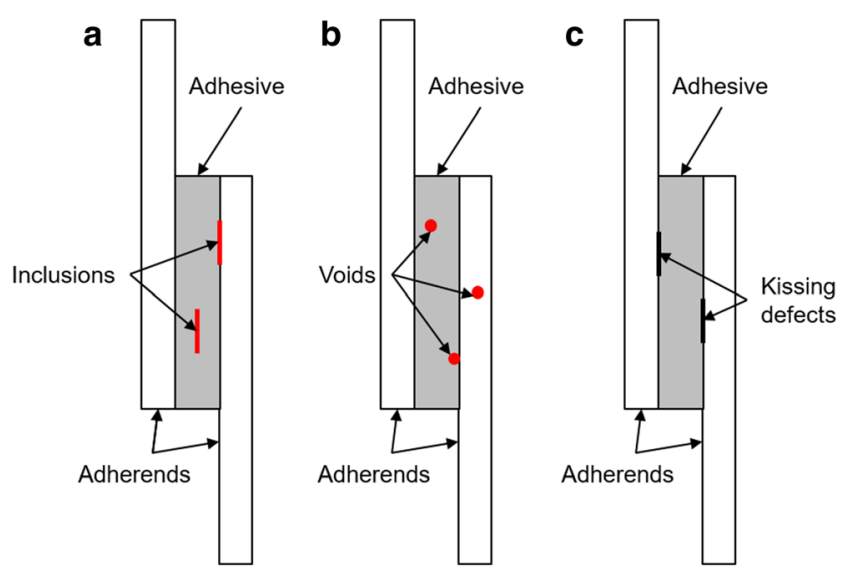

Fig. 2 Three categories of defects typically found in adhesive joints; (a) inclusions, (b) voids and (c) kissing defects 
over it. The second type are voids which are caused by the inclusion of air in the joint, see Fig. 2(b). These could occur between the adhesive and adherend during joint assembly or be found in the adhesive itself if air is introduced, e.g. during mixing of a two part adhesive. The final category of defect are kissing defects. Kissing defects are the result of improper adhesion between the adhesive and the adherend, as shown in Fig. 2(c), where the adhesive/adherend interface is not as strong as expected for that joint configuration [6]. A decreased level of adhesion leads to reduced joint strength and is a significant threat to structural integrity. As all components of the joint are present and in contact, kissing defects are the most difficult type of defect to detect using NDE techniques. The present paper focusses on the detection of kissing defects as these are the most challenging defect to detect as they provide very little material property contrast to aid NDE techniques in their detection.

Voids and inclusions are of known origin and are therefore relatively easy to recreate in the laboratory, however, the exact cause of kissing defects is unknown. Possible causes are thought to be contamination, abnormality in the adhesive chemistry or curing process, moisture ingress, residual stresses, or a combination of these factors [7, 8]. Several studies have focused on the recreation of kissing defects in the laboratory [9]. Most have categorised kissing defects into two types, dry contact and liquid layer [10]. In a dry contact recreation, adhesive is applied to one adherend and cured. The other adherend is put in position and held in place by compressive loading. In the case of a dry contact bond no actual adhesion occurs between the adhesive and adherend. A liquid layer defect is achieved by the introduction of a thin layer of a contaminant such as grease at the adhesive/adherend interface. The thickness of the contaminant is much thinner than the thickness of the adhesive layer but has a detrimental effect on the strength of the joint as the level of adhesion is reduced by up to $80 \%$ of the original bond shear strength over the contaminated area [11].

\section{NDE of Adhesive Bonds}

Several standards exist for the NDE of adhesive bonds in composite materials, these include: ASTM E1495/ E1495M (acousto-ultrasonics), ASTM E2582-7 (flash thermography) and ASTM STP1184 (acoustic emission). However, it is widely accepted that conventional NDE techniques are not currently able to identify all types of defects that occur in adhesive bonds, specifically kissing bonds [12]. A brief outline of some of the techniques investigated to detect defects in adhesive bonds beyond those of the standards is given below.

Acousto-ultrasonics (AU) is a combination of acoustic emission and ultrasound; an ultrasonic source is used to 'load' the sample and the ability of a component to transfer strain energy introduced by the small stresses caused by the ultrasonic excitation is measured. A correlation was found between $\mathrm{AU}$ measurements and the strength of lap shear bonded composites [13]. However, AU does not allow defects to be visualised, but rather gives a measure of their effect on the overall strength of the bond, and so does not aid in a targeted remediation methodology.

A wide range of literature exists focussing on the development of advanced ultrasound (UT) techniques for the inspection of adhesive bonds [14]. Standard C-scan UT is currently used for NDE of bonded joints in the aerospace industry during manufacture [15]. However, the time consuming point by point nature and water coupling of this approach make it difficult to implement on site. Application of Lamb waves for identification of debonds in adhesive bonds is the subject of several investigations, as they may be used without direct access to the joints, e.g. [16, 17]. Lamb waves (or plate waves) may be used for inspection of materials where their thickness is a few wavelengths of the applied wave. The waves propagate parallel to the surface of the material throughout the thickness of the material creating localised regions of tension and compression enabling detection of defects where the elastic material properties differ from the surrounding bulk properties [18].

Shearography has been used for identification of defects in adhesive joints in materials including aluminium and CFRP using flat bottom hole defects in the bond lines [19]. Shearography is able to identify a range of defects including inserts and adhesive starvation in adhesive bonds in rubber, CFRP and ceramics [20]. The main drawback found with shearography was that the interpretation of the fringe pattern results needs to be carried out by trained personnel. There has been some work towards automation of the procedure [21] which is still ongoing.

As mentioned previously, acoustic emission [22] is currently used to detect bonding defects in the Mk III carrier once the whole tank has been constructed. Acoustic emission has also been used to assess bonding integrity for a rocket motor case [23]. Finite element analysis (FEA) was incorporated with the acoustic emission data to provide threshold readings to relate an acoustic emission signal rate to a threshold level that correlates to a strain distribution over the bond.

Thermographic NDE has the ability to inspect large areas in short periods of time with easily interpretable results [9]. Thermography requires the creation of a temperature gradient between defect and non-defect regions to enable defect detection [24]. In the literature thermographic techniques have been tested for specific applications of bonded joints. A composite truck box with adhesively bonded joints was tested using pulsed thermography (PT) to identify mechanical damage in the composite panels and disbonds in the adhesive joints [25]. The bond defect found using PT was then identified as a starved bond where insufficient force was applied to fully adhere the bond; this may therefore be considered as a void 
or delamination of the bond line. As this type of defect has a volume filled with air it cannot be considered a kissing defect, and hence can be identified. Bonded joints between CFRP reinforcement patches and concrete have been assessed using PT to identify a range of defect types including unbonding, where no adhesive is present, delaminations, and debonding [26]. Variations in the pulse duration and the distance from the heat lamp to the sample were studied and minimum strength and pulse durations were suggested to study such composite repairs. Omar et al. [27] used thermography to study bond integrity of plastic welded joints. Results show this method was able to identify areas of delamination in the bonded region, and even though the defects were classed as kissing defects [27] it appeared that the defects have a volume, and hence are not strictly speaking kissing defects as defined in the present paper.

In the literature thermographic approaches have shown promise for the inspection of adhesively bonded joints. Thermography is able to detect defects where there is a variation between defect and surrounding material thermal properties [28]. Kissing defects do not provide such a contrast, therefore to be able to detect kissing defects using thermography it is necessary to enhance the thermal contrast between the defect and the surrounding material.

\begin{abstract}
Aim
The aim of the current research is to explore the potential of using active thermographic methods, specifically pulsed phase thermography (PPT) [28], to develop a reliable method of identifying kissing defects in the adhesive bonds found in the secondary membrane of GTT Mk III carriers. The goal being to define the technology required to make a robust and portable device for NDE of adhesive bonds in a shipyard during the construction stage. The work builds on that presented in [29] for specific application on the GTT Mk III carriers.
\end{abstract}

\section{Pulsed Phase Thermography}

A schematic of the experimental set up for PPT is given in Fig. 3. As only single sided access is available for the Triplex joints the inspection must be carried out using reflection mode PPT where the heat source and infrared (IR) detector are on the same side of the bond. When dealing with such thin materials the impact of using reflection mode compared to through transmission mode (with the detector and heating on opposite sides of the component) on the identification of defects is negligible. PPT involves the application of a pulse of heat to the surface of the material. Once the surface is heated an IR detector is used to monitor the surface temperature evolution as the heat front propagates through the thickness of the material. Where the material is
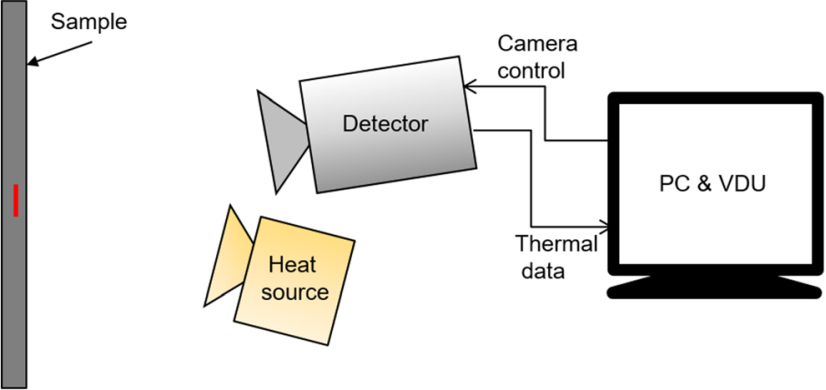

Fig. 3 Schematic of pulse phase thermography experimental set-up

laterally uniform across the area of inspection the heat front will propagate uniformly and the surface temperature will remain uniform. However, where there is a region of differing thermal properties, such as if there was a void below the surface, the heat propagation will be affected. The variation in heat front propagation local to such a defect will result in non-uniformity in the surface temperature over the defect. From this non-uniformity the location and extent of a defect may be inferred. While for shallow defects, that create a strong thermal contrast, the defects can be visible directly in the recorded thermal data it is generally necessary to post process the thermal decay data into phase data using a fast Fourier transform. The application of the FFT involves processing the data from each pixel through time into phase data [30].This enables external effects such as surface reflections and non-uniform heating to be reduced and deeper or less strongly contrasting defects to be revealed.

All thermography based techniques rely on there being a contrast in material and defect thermal properties. Kissing defects however, offer little or no thermal contrast, thus would not normally be identified using this approach. A novel aspect of this work is to apply a small non-destructive load to open kissing defects to enhance their thermal contrast and enable defect detection. The Triplex bond lends itself to this approach as there is a stiffness mismatch between the flexible and rigid Triplex, i.e. between the two adherends of the joint and the flexible Triplex of the accessible adherend. When the flexible Triplex is loaded it will more easily deform than its rigid counterpart, enabling a kissing defect to be opened. Furthermore, due to the low level of loading required to elastically deform the flexible Triplex material it may be possible to use a vacuum to open existing defects to enable their detection. The final concept would be to have a PPT inspection system contained within a vacuum hood, making a portable practical tool as shown in Fig. 4, labelled vacuum position 1 . However, due to the cooled nature of the photon detector used, initial tests have applied the load to the rear of the sample while inspection is carried out on the opposite surface, as shown in Fig. 4, labelled vacuum position 2. The initial setup required two sided access to the bond which would limit the application of the technique in its current form, however this enabled a proof of concept to be investigated. It would be 
Fig. 4 Vacuum loading options on CFRP-Triplex bond with simulated kissing defect

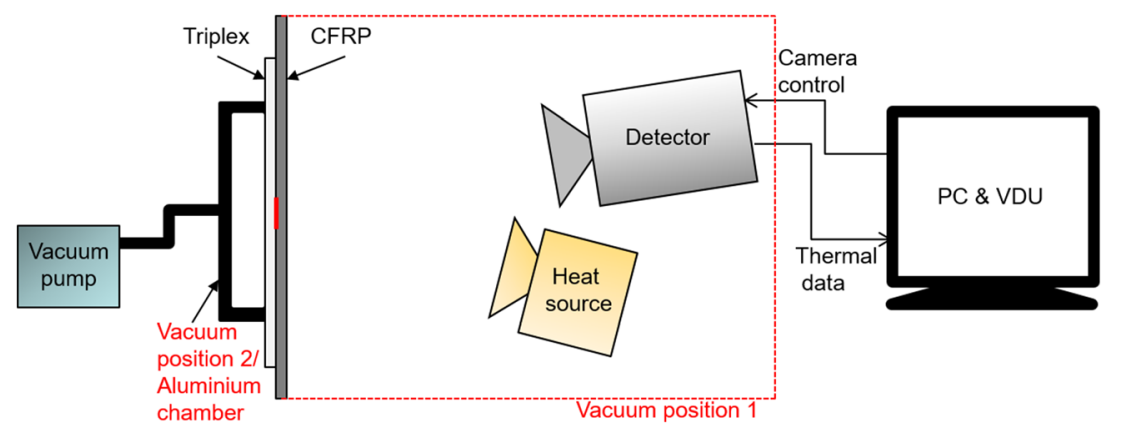

anticipated that should the design be taken into industry the type of detector would be changed to be a microbolometer which would enable the PPT setup to be incorporated into the vacuum design, creating a tool requiring only single sided access. A microbolometer can be more easily used in a vacuum as it does not require cooling, unlike the photon detector currently used and would simply need power and data cables to exit the vacuum. Although the microbolometer and heat pulse would generate heat it is anticipated this would quickly dissipate, particularly when moving the device between inspection sites where the vacuum would be lost. Some initial work has been carried out to examine the performance of microbolometers in vacuums. This has shown that a careful selection of the microbolometer type and lens is necessary. Further, at higher vacuum level the electronics can be affected; however for this application it is not necessary to apply such a high level vacuum.

\section{Methodology}

Initial trials were conducted to demonstrate the ability of the experimental procedure for the identification of features within a Triplex bond with inspection through the Triplex material. This was carried out on a rigid Triplex - flexible Triplex (RTFT) bond with a polytetrafluoroethylene (PTFE) insert in the bond line. The PTFE insert was not meant to simulate a defect but rather to provide a known feature within the bond for identification to establish the suitable thermographic experimental parameters, including heat stimulus required, camera recording frequency and duration of data collection.

A second test piece representative of the bonds found in LNG carriers was produced to demonstrate the concept of kissing defect detection with the application of a vacuum load. Although the initial RT-FT joint thermally simulates the LNG carrier joint, it does not mechanically simulate the joint. Within the LNG carrier the Triplex is adhered to the rigid Triplex and thick insulation blocks, thus a stiffness mismatch is present between the two adherends of the bond. The stiffness mismatch has been recreated for laboratory testing using a CFRP plate as the second adherend. The sample consisted of the flexible Triplex material adhered to a CFRP plate with layup $\left[\begin{array}{ll}0 & 90\end{array}\right]_{\mathrm{s}}$, as shown in Fig. 4. In the laboratory trials the bond is inspected from the CFRP side, although in practice inspection will occur through the flexible Triplex, as in the first round of trials. The adhesive used for the simulated joint was an epoxy based adhesive, creating a total bond thickness of $1.4 \mathrm{~mm}$. A $20 \mathrm{~mm}$ square patch of silicon grease contamination was introduced to the CFRP side of the bond with total bond dimensions of $250 \times 150 \mathrm{~mm}$. The silicon grease created a liquid layer style simulated kissing defect. The vacuum was applied, as shown in Fig. 4 as vacuum position 1, by using a small portable aluminium chamber, which was attached to the sample using sealant tape. A standard laboratory vacuum pump was used to apply the vacuum; the levels of vacuum pressure achieved are defined relative to the pump performance, i.e. $100 \%$ is maximum vacuum applied by the pump which creates a pressure of approximately 0.15 bar and $0 \%$ is atmospheric pressure, approximately 1 bar.

A FLIR 5500SC photon detector was used to collect the thermal data, which comprises a $320 \times 256$ array of $\mathrm{InSb}$ detectors which are sensitive in the wavelength range of 3$5 \mu \mathrm{m}$. The detector has a noise equivalent thermal difference (NETD) of $20 \mathrm{mK}$. Data was collected using the full frame of detectors with a frame rate of $100 \mathrm{~Hz}$ and a $10 \mathrm{~s}$ recording time. The data was collected and processed in the PPT phase data using the detector manufacturer's propriety software Altair and AltairLI. Settings were established during the initial trials on the RT-FT PTFE sample. The heat source was a

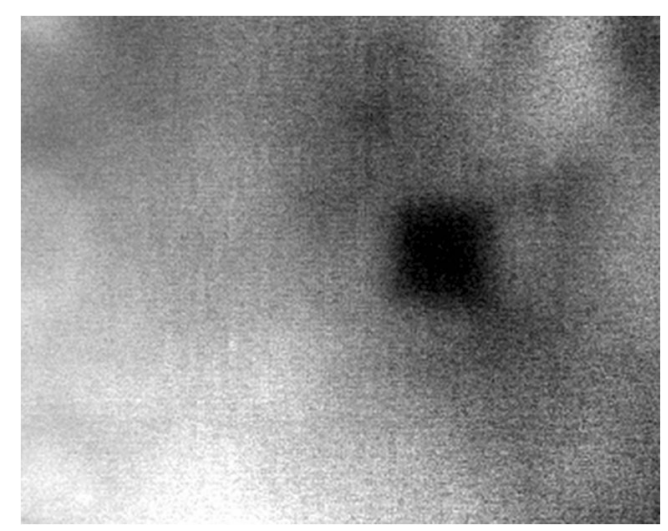

Fig. 5 PPT phase data identifying PTFE insert in Triplex bond through inspecting through rigid Triplex 
Fig. 6 PPT phase data for the CFRP/Triplex bonded sample (a) unloaded and (b) full vacuum applied to the rear of the sample
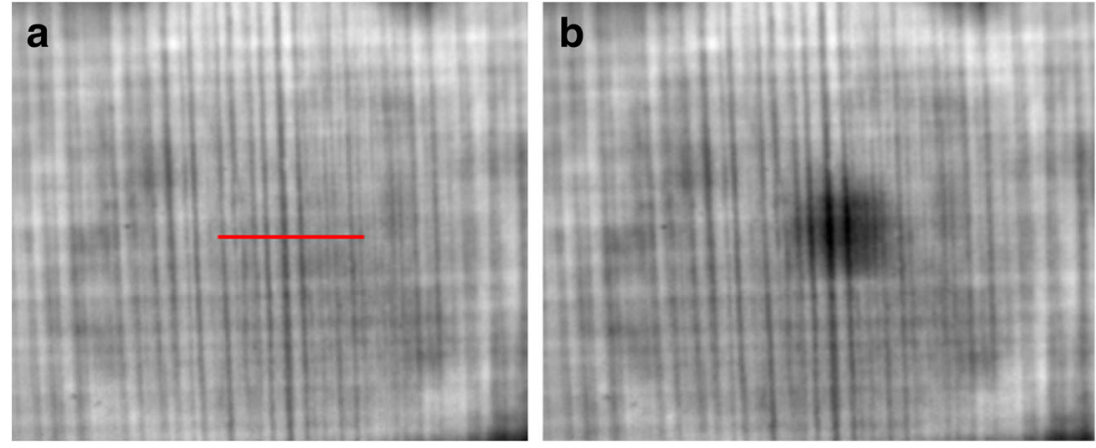

1000 J Bowens Gemini 1000 Pro photographic flash lamp. The flash was positioned $200 \mathrm{~mm}$ from the sample to provide approximately uniform heating across the observed region. The detector was positioned $270 \mathrm{~mm}$ from the sample to provide a suitable observation window over the defect site. The detector and flash were manually triggered and it was ensured that the single pulse from the flash was captured within the recording. As the duration of the pulse was $2.1 \mathrm{~ms}$ and detector frame rate is $100 \mathrm{~Hz}$ therefore, despite manual triggering, the flash is assumed to only occupy one frame of the recording. The pressure of the vacuum pump was varied between $0 \%$ and $100 \%$ in $20 \%$ increments and the PPT inspection repeated at each vacuum level.

\section{Results}

The PTFE is clearly identified in the RT-FT bond, as shown in the PPT phase data in Fig. 5. This initial test confirmed the PPT setup and experimental procedure selected was suitable for identification of defects with inspection through the Triplex. Using this defined procedure the second joint configuration containing the stiffness mismatch between the FT and

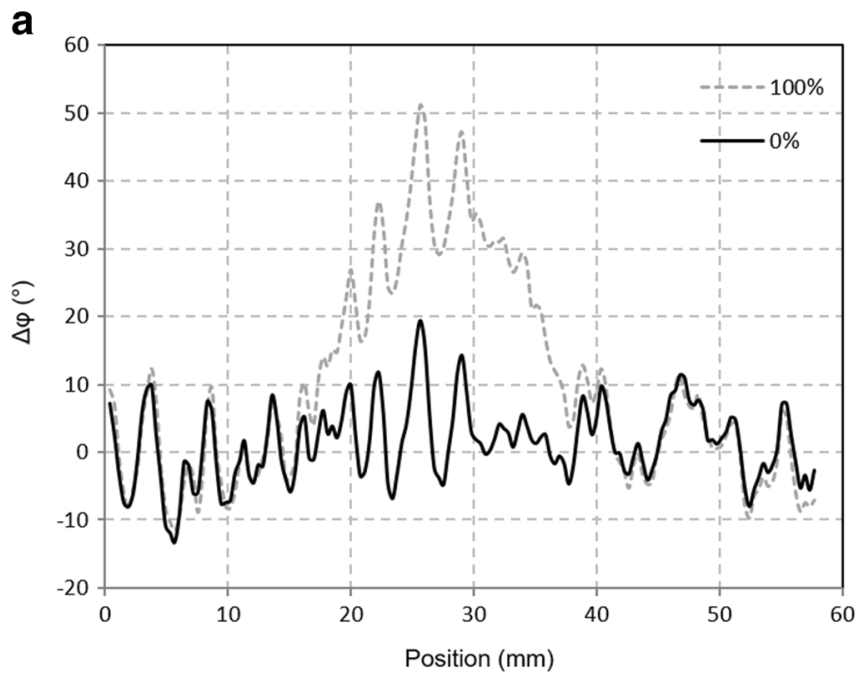

the CFRP was then inspected with the application of vacuum loading for kissing defect detection. Figure 6(a) and (b) show the PPT phase results of the defect region with no load applied and full $(100 \%)$ vacuum loading. The lighter circular ring visible in the edges of the images is due to the presence of the aluminium vacuum chamber attached to the rear of the sample. It is clear that without the addition of load the silicon grease contamination is not visible in the phase data, as is expected for a kissing defect. When the vacuum is then applied the defect becomes easily identifiable in the centre of the image in Fig. 6(b). This is emphasised in the profile data taken horizontally across the centre of the defect position, as shown in Fig. 6(a), for the fully loaded and unloaded conditions. The profile plot, in Fig. 7(a), also demonstrates that the regions away from the defect, i.e. the well bonded regions, are unaffected by the application of the vacuum, hence the defect is not propagated by the loading and the technique is non-destructive. It should be noted that an unloaded image was taken after the full vacuum was applied and the profile returned to that obtained prior to loading, demonstrating that permanent deformation had not occurred in the flexible Triplex by the vacuum loading. The joints were also inspected several times, each time giving consistent results further ensuring that the

b

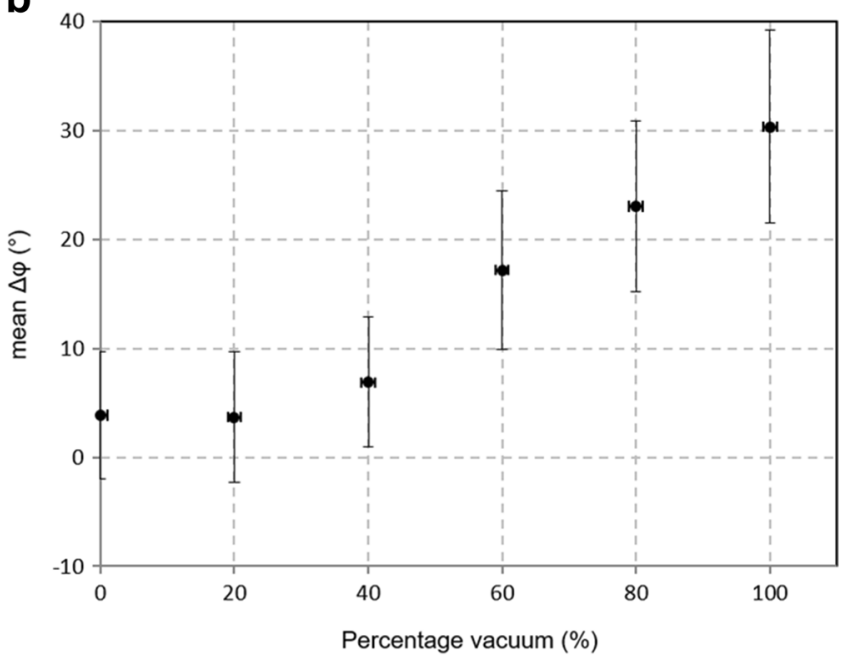

Fig. 7 (a) phase contrast profiles taken across the defect region under vacuum loading conditions of $100 \%$ vacuum and $0 \%$ vacuum and (b) the mean phase contrast between defect and non-defect regions taken across the width of the defect related to partial vacuum percentage applied 
defect was not propagated during the vacuum loading. Fig. 7(b) shows the mean phase contrast between the defective and nondefective regions for each vacuum partial pressure applied. The defect becomes identifiable in the mean phase contrast data at just $60 \%$ of vacuum pressure, thereby highlighting the low level of load required to generate such results. The level of loading required to open the kissing defect is dependent on the stiffness of the material and the size and geometry of the defect. Therefore, should a maximum tolerable defect be determined to be smaller than that tested in the present paper, it would be necessary to ensure sufficient load was applied to reveal such a defect. Definition of such a threshold size is beyond the scope of the current work.

Recently [31], a thermographic technique known as thermoelastic stress analysis (TSA) has been applied on site. TSA requires loading, usually in a test machine in a laboratory environment. In [31] the natural frequency of the system is used to provide the cyclic load, This approach would also have the benefit of opening the defect to make it more detectable. However, the prospect of exciting the LNG carrier tank at its natural frequency, even locally, presents a major challenge and hence TSA was deemed not be a relevant approach, but is an interesting area for further research.

\section{Conclusion}

Triplex joints representative of those found in the GTT Mk III LNG carrier were studied using PPT. Kissing defects, which were of specific interest, were simulated using silicon grease. To provide sufficient stiffness to simulate a real Triplex bond the flexible Triplex was adhered to a CFRP panel. A vacuum load was applied to the flexible Triplex, exploiting the stiffness mismatch between the adherends, to facilitate the opening of the defect. PPT was carried out on the CFRP surface. Sufficient load was applied to the sample to begin to open the $20 \mathrm{~mm}$ defect at just $60 \%$ of full vacuum. Even under the application of full vacuum loading the profile data demonstrated that the defect did not grow and after removal of the load the defect closed, thus no plastic deformation was caused. To allow the Triplex joints on the carriers to be inspected it would be necessary to position the PPT setup within the vacuum chamber using an uncooled bolometer style detector to provide the single sided access required. It is necessary to assess the performance of bolometers in a vacuum environment and initial unpublished work in a vacuum chamber has shown that it is possible to collect data under such circumstances with minimal impact on the bolometer function. It is therefore considered that a promising new portable approach for the detection of defects on site has been demonstrated with the potential to be applied in a wide range of production environments.
Acknowledgements This work was supported by the Lloyds Register Educational Trust and the Engineering and Physical Sciences Research Council. The authors particularly acknowledge the contribution and insight of David Howarth, formerly of Lloyd's Register, Materials Welding and NDE Marine Technical Policy Group, London, UK.

Open Access This article is distributed under the terms of the Creative Commons Attribution 4.0 International License (http:// creativecommons.org/licenses/by/4.0/), which permits unrestricted use, distribution, and reproduction in any medium, provided you give appropriate credit to the original author(s) and the source, provide a link to the Creative Commons license, and indicate if changes were made.

\section{References}

1. Energy UK (2014) Electricity Generation http://www.energy-uk. org.uk/energy-industry/electricity-generation.html. Accessed 16 Jan 2017

2. International Gas Union (2016) World LNG Report - 2016 Edition http://www.igu.org/publications. Accessed 27 Jan 2017

3. Howarth, D. (2006) Adhesive bonding in LNG ship construction. Lloyd's Register internal report

4. Central commission for the navigation of the rhine/ Oil companies international marine forum (2010) International safety guide for inland navigation tank-barges and terminals, 1st Edn. Chapter 33, pp 505-518

5. Mattox D M (2010) Handbook of physical vapor deposition (PVD) processing, 2nd Edition. Oxford: William Andrew Applied Science Publishers. p. $54-56$

6. Brockmann W, Geiss PL, Klingen J, Schroder B (2009) Adhesive bonding: Adhesives, applications and processes. Wiley-Vch, Germany

7. Adams RD, Cawley P (1988) A review of defect types and nondestructive testing techniques for composites and bonded joints. NDT Int 21(4):208-222

8. Marty PN, Desai N, Andersson J (2004) NDT of kissing bond in aeronautical structures. In: 16th world conference on NDT, Montreal

9. Roach D, Rackow K, Duvall R (2010) Innovative use of adhesive interface characteristics to nondestructively quantify the strength of bonded joints. In: Proceedings of the 10th European conference on non-destructive testing. Moscow

10. Yan D, Drinkwater BW, Neild SA (2009) Measurement of the ultrasonic nonlinearity of kissing bonds in adhesive joints. NDT\&E Int 42:459-466

11. Brotherhood CJ, Drinkwater BW, Guild FJ (2002) The effect of compressive loading on the ultrasonic detectability of kissing bonds in adhesive joints. J Nondestruct Eval 21(3):95-104

12. Karbhari VM (2013) Non-destructive evaluation (NDE) of polymer matrix composites - techniques and applications. Woodhead Publishing, Composite Science and Engineering Series

13. Karhnak SJ, Duke JC (1994) Predicting performance of adhesively bonded joints on acousto-ultrasonic evaluation. In: composite bonding ASTM STP 1227. Philadelphia

14. Ehrhart B, Valeske B, Muller CD, Bockenheimer C (2010) Methods for the quality assessment of adhesive bonded CFRP structures - a resume. We.5.B.2. 2nd international symposium on NDT in aerospace 2010, Hamburg

15. Huke P, Focke O, Falldorf C, von Kopylow C, Bergmann RB (2010) Contactless defect detection using optical methods for non destructive testing. In 2 nd international symposium on NDT in aerospace 2010. Hamburg

16. Cuc A, Giurgiutiu V (2004) Disbond detection in adhesivelybonded structures using piezoelectric wafer active sensors. SPIE 11th Annual Symposium on Smart Structures and Materials and 
9th Annual International Symposium on NDE for Health Monitoring and Diagnostics, March 2004, USA

17. Heller K, Jacobs LJ, Qu J (2000) Characterization of adhesive bond properties using lamb waves. NDT\&E International 33(8):555-563

18. Su Z, Ye L, Lu Y (2006) Guided lamb waves for identification of damage in composite structures: a review. J Sound Vib 295(3-5): 753-780

19. Hung MYY, Chen YS, Ng SP (2007) Review and comparison of shearography and pulsed thermography for adhesive bond evaluation. Opt Eng 46(5):051007

20. Hung YY, Chen YS, Ng SP, Liu L, Huang YH, Luk BL, Ip RWL, Wu CML, Chung PS (2009) Review and comparison of shearography and active thermography for nondestructive evaluation. Mater Sci Eng R 64(5-6):73-112

21. Hung YY, Ho HP (2005) An optical measurement technique and applications. Mater Sci Eng: R 49(3):61-87

22. Schliekelmann RJ (1975) Non-destructive testing of bonded joints, recent developments in testing systems. Non-Destr Test 8:100-110

23. Rhee S-H, Hwang T-K (2009) Use of acoustic emission to identify the bonding status of a rocket motor case. In proceedings of ICCM 17. Edinburgh

24. Pickering SG, Chatterjee K, Almond DP, Tuli S (2013) LED optical excitation for the long pulse and lock-in thermographic techniques. NDT\&E Int 58:72-77
25. Schroeder JA, Ahmed T, Chaudhry B, Shepard S (2002) Nondestructive testing of structural composites and adhesively bonded composite joints: pulsed thermography. Compos Part A 33:1511-1517

26. Tashan J, Al-Mahadi R (2014) Bond defect detection using PPT IRT in concrete structures strengthened with different CFRP systems. Compos Struct 111:13-19

27. Omar M, Hassan M, Donohue K, Saito K, Alloo R (2006) Infrared thermography for inspecting the adhesion integrity of plastic welded joints. NDT\&E Int 39:1-7

28. Maldague X, Marinetti S (1996) Pulse phase infrared thermography. J Appl Phys 79(5):2694-2698

29. Tighe RC, Dulieu-Barton JM, Quinn S (2016) Identification of kissing bonds using infrared thermography. Int $\mathrm{J}$ Adhes Adhes 64:168-178

30. Maldague X (2001) Theory and practice of infrared technology for nondestructive testing. In: Chang K (ed) Wiley series in microwave and optical engineering. John Wiley \& Sons, Inc, Chichester

31. Tighe RC, Howell GP, Tyler JP, Lormor S, Dulieu-Barton JM (2016) Stress based non-destructive evaluation using thermographic approaches: from laboratory trials to on-site assessment. NDT\&E Int 84:76-88 